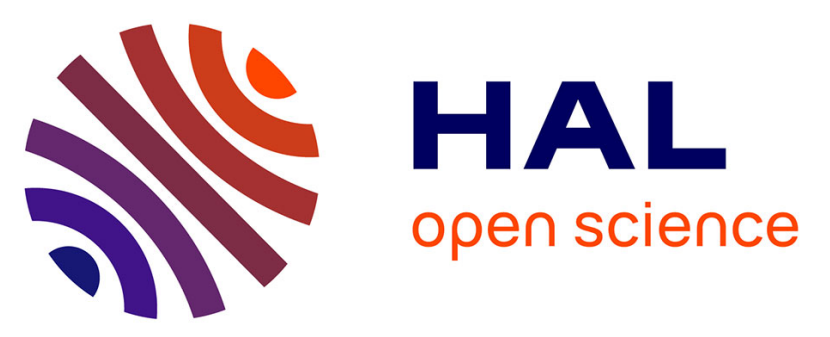

\title{
Closed-Form Expression of the Response Time of an Open Channel
}

\author{
S. Munier, Gilles Belaud, X. Litrico
}

\section{To cite this version:}

S. Munier, Gilles Belaud, X. Litrico. Closed-Form Expression of the Response Time of an Open Channel. Journal of Irrigation and Drainage Engineering-ASCE, 2010, 136 (10), p. 677 - p. 684. 10.1061/(ASCE)IR.1943-4774.0000241 . hal-00572351

\section{HAL Id: hal-00572351 \\ https://hal.science/hal-00572351}

Submitted on 1 Mar 2011

HAL is a multi-disciplinary open access archive for the deposit and dissemination of scientific research documents, whether they are published or not. The documents may come from teaching and research institutions in France or abroad, or from public or private research centers.
L'archive ouverte pluridisciplinaire HAL, est destinée au dépôt et à la diffusion de documents scientifiques de niveau recherche, publiés ou non, émanant des établissements d'enseignement et de recherche français ou étrangers, des laboratoires publics ou privés. 


\title{
Closed-form Expression of the Response-Time of an Open-Channel
}

\author{
S. Munier ${ }^{1}$, and G. Belaud ${ }^{2}$, and X. Litrico ${ }^{3}$
}

\begin{abstract}
Computing accurately the response time of an open-channel is of extreme importance for management operations on canal networks, such as feed-forward control problems. The methods proposed in the literature to approximate the response time do not always account for the influence of a cross-structure at the downstream end of a canal pool, which may have a significant impact on the response time. This paper proposes a new approach to compute the response time, accounting explicitly for the backwater and the feedback effects due to the downstream cross structure. The method provides a distributed analytical expression of the response time as a function of the characteristics of the canal (geometry, roughness) and of the downstream cross structure. A test canal with a weir or a gate at the downstream end is used to compare the new method with some others. Results show that the proposed expression accurately reproduces the response time for various backwater and downstream boundary conditions.
\end{abstract}

CE Database subject headings: Open channel flow, Analytical model, Response time, Flow control, Canal design.

\section{Introduction}

The response time of an irrigation canal or a regulated river is usually defined as the time required for the system to transit from an initial steady state to a final steady state

\footnotetext{
${ }^{1}$ Cemagref, UMR G-EAU, 361 rue J.F. Breton, B.P. 5095, 34196 Montpellier Cedex 5, France. E-mail: simon.munier@cemagref.fr.

${ }^{2}$ IRD, UMR G-EAU, Maison des Sciences de l'Eau, 300 Avenue Emile Jeanbrau, 34095 Montpellier Cedex 5, France. E-mail: belaud@msem.univ-montp2.fr.

${ }^{3}$ Cemagref, UMR G-EAU, 361 rue J.F. Breton, B.P. 5095, 34196 Montpellier Cedex 5, France. E-mail: xavier.litrico@cemagref.fr.
} 


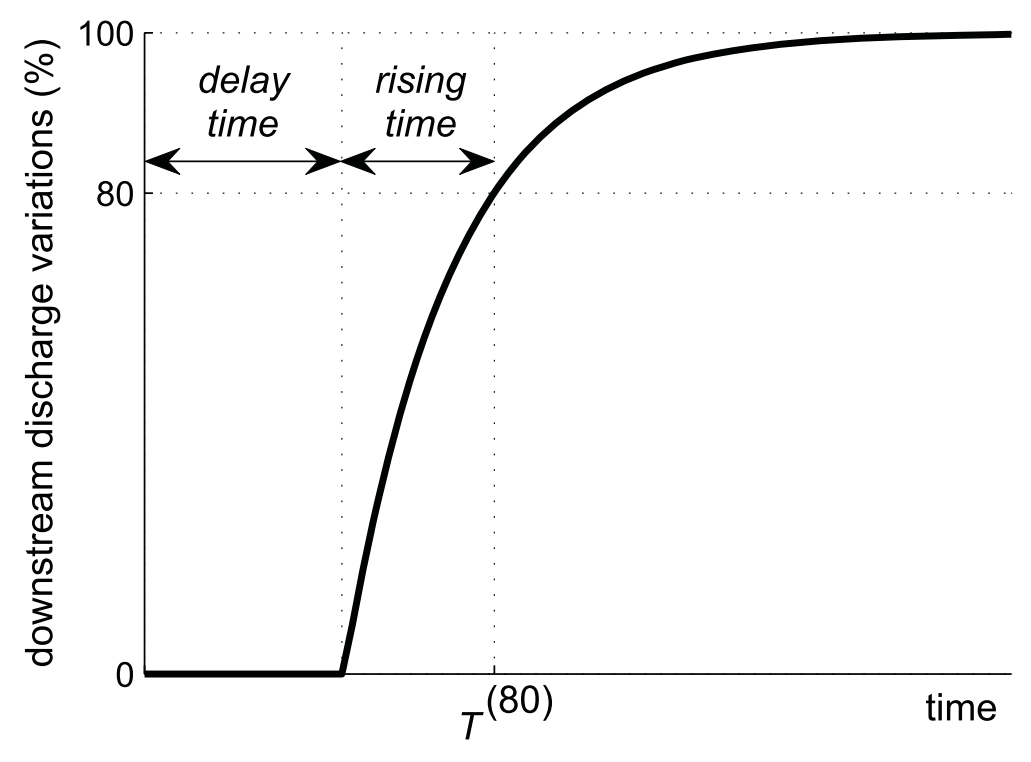

Fig. 1. Delay time and rising time for a step input.

(Ankum 1995). The time can be a few hours in medium-size canals or a few days in large canals or rivers and it depends on the discharge and water depth all along the canal pool. It is key information for managers, especially when they have to release water into the system so as to achieve pre-specified distribution schedules, which is called open-loop control.

The notion of response time is not clearly defined in the literature. In the following, the response time for a step input is defined as the sum of two terms: the delay time and the rising time (see Fig. 1). The delay time is the time at which the discharge increase is observed at the downstream end of the canal. The rising time is defined as the time required for the discharge to reach $\alpha \%$ of the maximum discharge increase. In this paper, the response time at $\alpha \%$ is denoted $T^{(\alpha)}$.

A standard approach is to approximate the response time to a step input by the time $T_{\Delta \mathcal{V}}$ necessary to supply a volume $\Delta \mathcal{V}$ of the dynamic storage, defined by the volume variation between the initial and the final steady state (Schuurmans 1990; Burt and Plusquellec 1990). As pointed out by Ankum (1995), this definition leads to underestimating the response time as it ignores the fact that the outflow increases with the storage and the wave travel time is neglected. Schuurmans (1990) improved this estimation by coupling the discharge and 
the water depth at the downstream end of the reach. This allowed him to compute an approximate expression of the response time at $\alpha \%$, denoted $T_{S c h}^{(\alpha)}$ in the following. The approximation performs well for short canals, which can be assumed to behave as storage basins. Schuurmans (1990) uses the diffusive wave equation diffusion effects in long canals. Ankum (1995) proposed a simple method to estimate the response time at $100 \%$, denoted $T_{A n k}$ in the following, considering that $T^{(50)}$ is close to the mean of $T^{(0)}$ and $T^{(100)}$. $T^{(0)}$ corresponds to the delay time, which is the time $T_{D W}$ required for the dynamic waves to travel through the canal. $T_{D W}$ is obtained by:

$$
T_{D W}=\frac{x}{C+V}
$$

where $x$ is the distance along the canal, $V$ is the mean flow velocity, $C=\sqrt{g A / T}$ the wave celerity with $g$ the gravitational acceleration, $A$ the wetted area and $T$ the top width. The author assumed that $T^{(50)}$ is equal to $T_{\Delta \mathcal{V}}$, which leads to the following expression of the response time:

$$
T_{A n k}=2 T_{\Delta \mathcal{V}}-T_{D W}
$$

Although these estimates give quick indicators for the canal response, it is useful to define the response time more accurately, namely by considering the effects of a cross structure at the downstream end of the reach.

Schuurmans et al. (1995) adopted a frequency approach to establish the transfer function of a reach in uniform flow. To account for the downstream cross structures, they assumed that the backwater part behaved as a reservoir, in which the water level is horizontal. Their model was able to correctly reproduce a step inflow on two canals with backwater curves. Based on their method, Bautista and Clemmens (1999) proposed an improved estimation of the canal dynamics by taking the travel time in the backwater part into account. For the two example canals used later in this paper, the results obtained by Bautista and Clemmens (1999) are very similar to those obtained using the dynamic storage approximation $\left(T_{\Delta \mathcal{V}}\right)$, 
despite a theoretically more accurate estimation of the response time. In the following, only $T_{\Delta \mathcal{V}}$ will be represented.

Strelkoff et al. (1998) studied the influence of the downstream boundary condition with different hydraulic structures at the downstream end of the canal. The steady state regime was considered non-uniform. They used a numerical model to estimate the response to a step inflow. They showed that not only the downstream water depth (and the backwater curve) had an influence on the flow dynamics, but also the nature of the hydraulic structure at the downstream end (feedback effect).

The backwater effect can be considered as a static effect due to a cross structure at the downstream end, whereas the feedback effect may be considered as a dynamic effect due to the local relation between downstream discharge and water depth variations. Some of the previous methods to estimate the response time take the backwater effect into account by considering a backwater part where the flow dynamics is modified. But none of them accounts for the feedback effect, which may lead to important under- or overestimation of the response time as shown further.

Following the idea of Schuurmans et al. (1995) and Litrico and Fromion (2004b), Munier et al. (2008) proposed a linear model, called LBLR for Linear Backwater Lag and Route, that considered separately backwater and feedback effects, both evaluated using the equation characterizing the downstream cross structure. The model was obtained by approximating the frequency response of a canal (Litrico and Fromion 2004a) and allowed the authors to calculate the response at any abscissa along the canal, which gave satisfactory results compared to full Saint-Venant's numerical solutions. This paper aims at proposing a closedform expression of the response time, derived from the LBLR model. The proposed formula explicitly accounts for the backwater and feedback effects due to the downstream boundary condition. Illustrations are given for different boundary conditions, for simulated and real data. Some design applications are proposed. 
Author-produced version of the article published in Journal of Irrigation and Drainage Engineering, 2010, Volume 136, Issue 10, pp. 677-684. The original publication is available at http://ascelibrary.aip.org/iro/ doi: 10.1061/(ASCE)IR.1943-4774.0000241

\section{Analytical calculation of the response time}

We first derive the LBLR moel, before illustrating the results on a test canal.

\section{Calculation of the response time using the LBLR model}

We consider a trapezoidal prismatic channel. Time and distance are denoted $t$ and $x$ respectively, the discharge $Q$ and the water depth $Y$ are functions of $(x, t)$. The equations of the flow dynamics are linearized around a non uniform reference regime defined by $Q_{0}$ and $Y_{0}(x)$ (see Fig. 2). Small variations in discharge and water depth are denoted $q(x, t)$ and $y(x, t)$ respectively. At the cross structure, the discharge is related to the water depth using the discharge equation:

$$
Q(X, t)=f(Y(X, t))
$$

In the following, Eqs. (4-5) are used to describe a weir and a gate respectively.

$$
\begin{aligned}
Q & =\sqrt{2 g} C_{w} L_{w}\left(Y-Z_{w}\right)^{3 / 2} \\
Q & =\sqrt{2 g} C_{g} L_{g} W_{g} \sqrt{Y}
\end{aligned}
$$

where $L_{w}$ is the weir length, $Z_{w}$ the sill elevation, $L_{g}$ the gate length, $W_{g}$ the gate opening, $C_{w}$ and $C_{g}$ some discharge coefficients. The discharge equation is used to determine the downstream water depth $Y_{X}=Y_{0}(X)$ corresponding to the reference discharge $Q_{0}$. In addition, the linearization of Eq. (3) leads to:

$$
q(X, t)=k y(X, t)
$$

where $k=\frac{d f}{d Y}$ is the feedback coefficient. One may obtain $k=\frac{3}{2} \frac{Q_{0}}{Y_{X}-Z_{w}}$ for a weir and $k=\frac{1}{2} \frac{Q_{0}}{Y_{X}}$ for a gate. The downstream boundary condition is then given by the couple $\left(Y_{X}, k\right)$.

In the method developed by Munier et al. (2008), the transfer function between the upstream discharge and the discharge at any location in the channel is approximated by a first-order-with-delay transfer function using the moment matching method. The backwater 


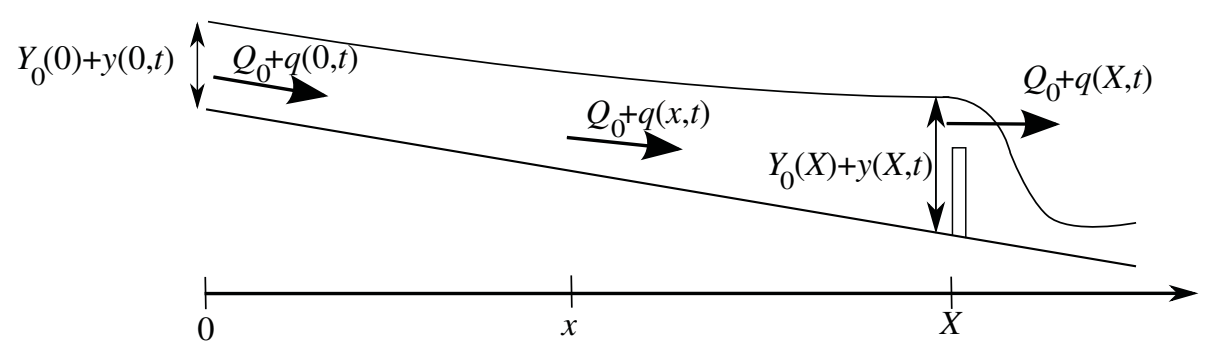

Fig. 2. General scheme of the considered channel.

effects are taken into account by decomposing the canal into two sub-pools and the feedback effects are represented by $k$. This leads to an analytical expression of the response to a step input at any location:

$$
q(x, t)=\left(1-e^{-\frac{t-\tau(x)}{K(x)}}\right)
$$

where $\tau(x)$ and $K(x)$ are obtained as closed-form expressions of the physical parameters of the pool (geometry, friction, reference discharge) and of the downstream boundary condition (downstream water depth and feedback coefficient). Appendix I describes how the transfer function is evaluated and approximated. Details of the calculation of $\tau(x)$ and $K(x)$ are given in appendix II.

The delay time is given by $\tau(x)$, whereas the rising time only depends on $K(x)$. According to Eq. (7), the response time $T_{L B L R}^{(\alpha)}$ is given by:

$$
T_{L B L R}^{(\alpha)}(x)=\tau(x)-K(x) \log \left(1-\frac{\alpha}{100}\right)
$$

The LBLR model has been implemented under the free software Scilab (www.scilab.org) and the files needed to compute the response time $T_{L B L R}^{(\alpha)}$ are available on request.

\section{Application to a test canal}

In order to compare the different methods of response time calculation, we use the test canal proposed by Strelkoff et al. (1998). The characteristics of the test canal are presented in Table 1.

The test canal considered here is rectangular (bank slope $m=0$ ) but the analytical ex- 
Table 1. Characteristics of the test canal.

\begin{tabular}{|c|c|c|c|c|c|c|}
\hline $\begin{array}{c}\text { Reference } \\
\text { discharge } \\
Q_{0}\end{array}$ & Length & Width & $\begin{array}{l}\text { Bank } \\
\text { slope }\end{array}$ & $\begin{array}{c}\text { Bottom } \\
\text { slope } \\
S_{b}\end{array}$ & $\begin{array}{c}\text { Manning } \\
\text { coefficient } \\
n\end{array}$ & $\begin{array}{c}\text { Normal } \\
\text { depth } \\
Y_{n} \\
\end{array}$ \\
\hline $1.9 \mathrm{~m}^{3} / \mathrm{s}$ & $2300 \mathrm{~m}$ & $2 \mathrm{~m}$ & 0 & 0.00044 & $0.014 \mathrm{sm}^{-1 / 3}$ & $1.00 \mathrm{~m}$ \\
\hline
\end{tabular}

pression of the response time presented further includes the case of a trapezoidal canal. The reference step response is calculated using SIC, a software that discretizes the Saint-Venant equations using a Preissmann scheme (Strelkoff et al. 1998; Baume et al. 2005). In the following, the time step and the space step are chosen in order to ensure an accurate simulation of the flow dynamics (Courant number close to unity). The corresponding response times are denoted $T_{S I C}^{(\alpha)}$.

Results are computed for three different downstream boundary conditions. The first one is defined by the Manning equation and represents a uniform flow. The two others are the weir and the gate used in Strelkoff et al. (1998). The weir is $21 \mathrm{~m} \mathrm{long}$, the sill elevation is $1.11 \mathrm{~m}$ and the discharge coefficient is 0.4 . The gate is $2 \mathrm{~m}$ wide, its opening is $0.32 \mathrm{~m}$ and its discharge coefficient is 0.6. Both structures are considered in free flow. The weir and the gate have been calibrated so that the water depth at the downstream end of the canal is equal to $1.25 Y_{n}$. In both cases the backwater curve is the same, leading to the same backwater effects. Yet, Strelkoff et al. (1998) showed that the step response is drastically different between both structures, which may be due to different feedback effects.

Graphs 3 and 4 illustrate the response to a step input calculated by SIC compared to the one calculated by the LBLR model. The step response for the uniform case (without any cross structure at the downstream end) is also represented. The comparison with the uniform case shows that the downstream cross structure can have a large impact on the flow dynamics. Both canals have the same backwater and the large difference between their responses is due to feedback effects. The LBLR model accurately simulates the step response in both cases.

\section{Results and discussion}




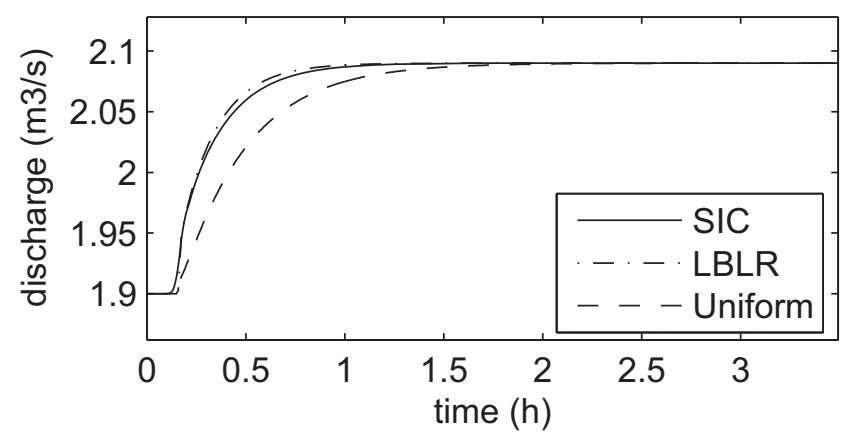

Fig. 3. Step response with a weir at the downstream end.

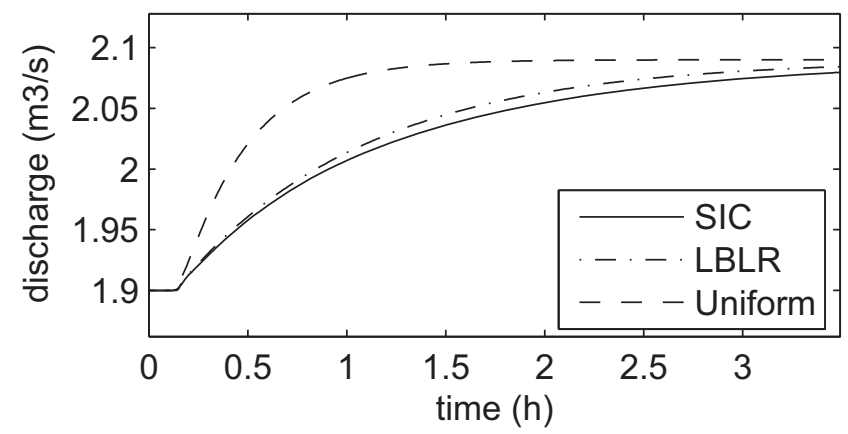

Fig. 4. Step response with a gate at the downstream end.

\section{Computation of the response time with the different methods}

The response time for the test canal has been calculated using the different methods presented in the review section. Figs. 5 and 6 show, for the weir and for the gate respectively, the evolution of the response time with respect to $\alpha$, calculated using SIC or the LBLR model.

The LBLR method leads to a very good approximation of $T^{(\alpha)}$ for all values of $\alpha$. It is able to accurately account for backwater and feedback effects. Here, the relative error of $T_{L B L R}^{(90)}$ compared to $T_{S I C}^{(90)}$ is only $11 \%$ for the weir and $16 \%$ for the gate.

The response times calculated with the other methods $\left(T_{D W}, T_{\Delta \mathcal{V}}, T_{A n k}, T_{S c h}^{(\alpha)}\right)$ are also represented on Fig. 5 and 6 . As Ankum (1995) suggested, we assume that $T_{D W}$ and $T_{\Delta \mathcal{V}}$ correspond to $\alpha=0$ and $\alpha=50$ respectively.

The method developed by Schuurmans (1990), which does not account for the feedback effects, provides quite good results for the weir, but not for the gate. Indeed, a variation in 
Author-produced version of the article published in Journal of Irrigation and Drainage Engineering, 2010, Volume 136, Issue 10, pp. 677-684.

The original publication is available at http://ascelibrary.aip.org/iro/

doi: 10.1061/(ASCE)IR.1943-4774.0000241

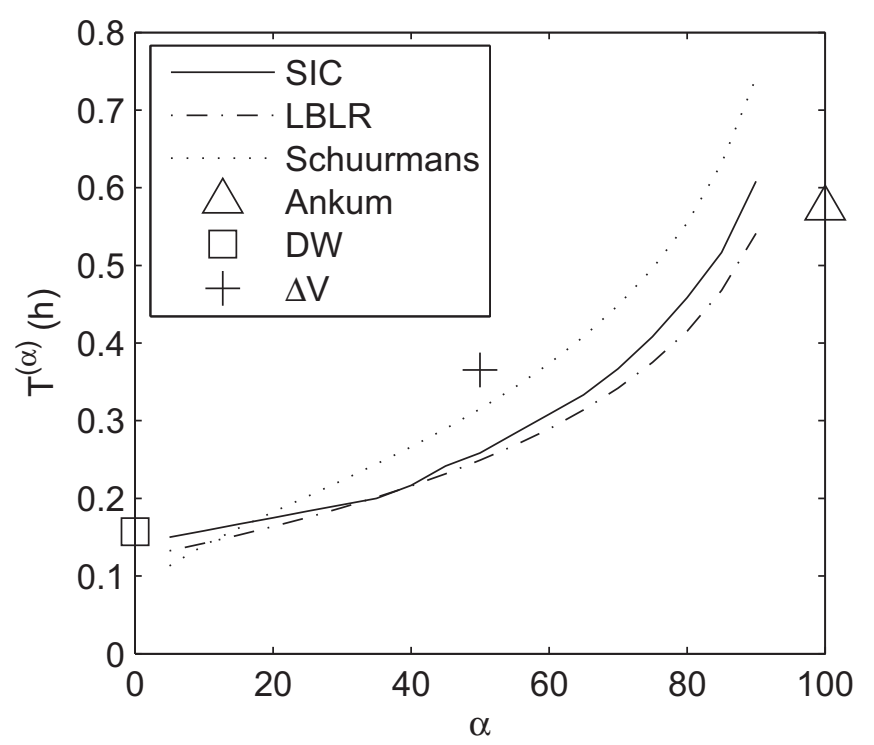

Fig. 5. Response time at $\alpha \%$ with respect to $\alpha$, with a weir at the downstream end.

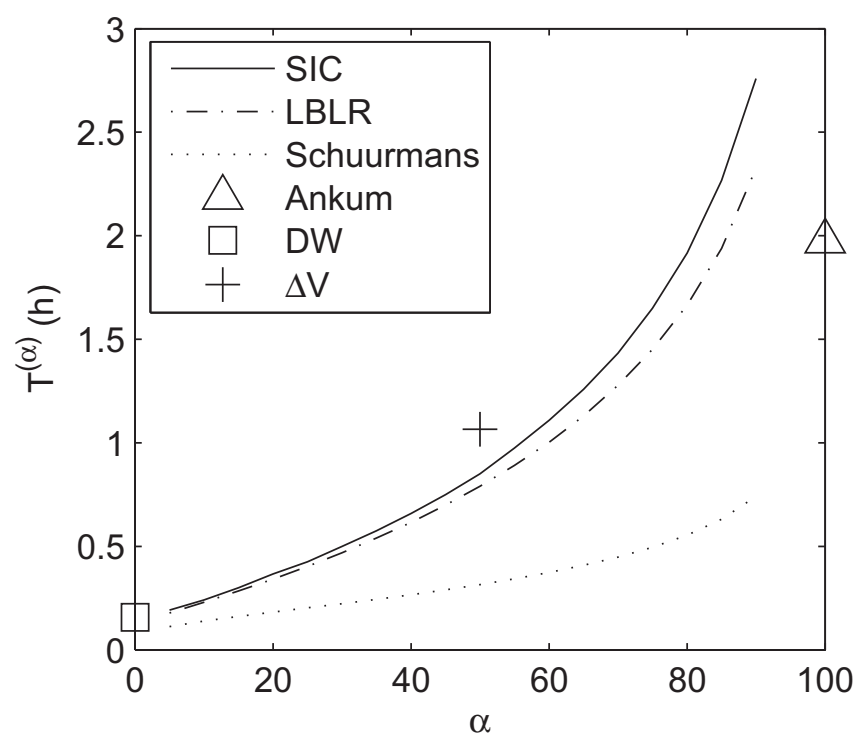

Fig. 6. Response time at $\alpha \%$ with respect to $\alpha$, with a gate at the downstream end.

the upstream discharge implies a smaller variation in the downstream water depth for the weir than for the gate. This is due to the fact that the feedback coefficient $k$ is larger in the case of the weir, which provides a better control of the downstream level.

These graphs also show that $T_{D W}$ is quite the same in both cases and is suitable to estimate $T^{(0)}$. Besides, $T_{\Delta \mathcal{V}}$ varies a lot between both cases, but remains close to $T^{(50)}$. 


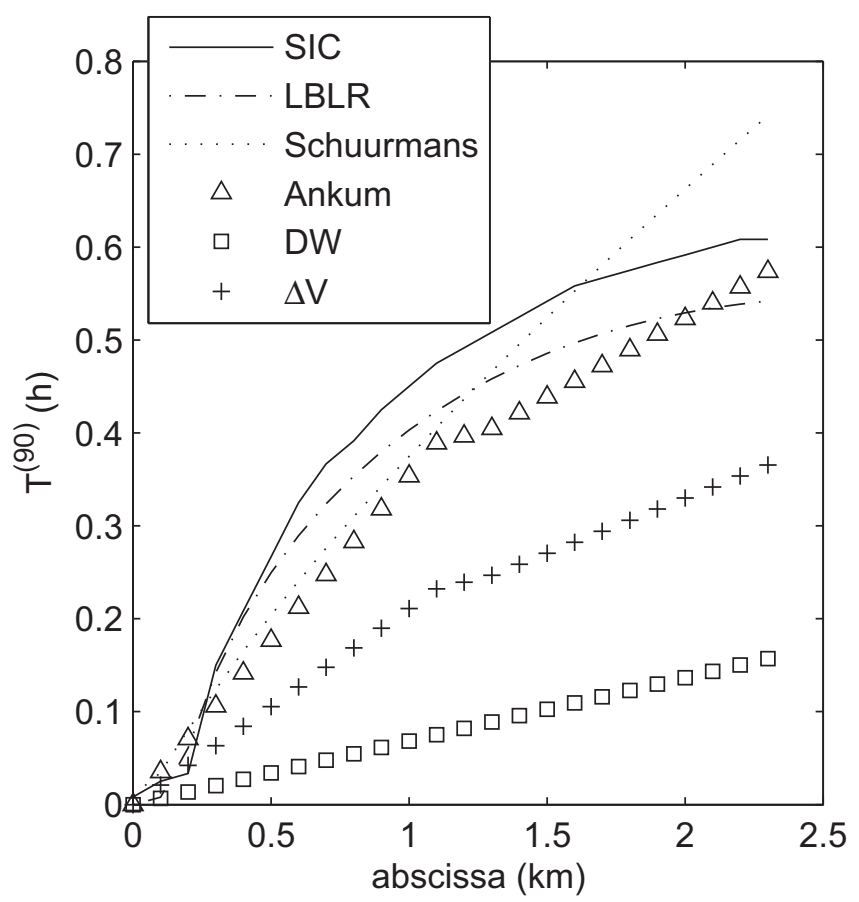

Fig. 7. Response time at $90 \%$ all along the channel with a weir at the downstream end.

In fact, the method to compute $T_{\Delta \mathcal{V}}$ uses the volume variation between the initial and final steady states. This requires the calculation of the water depth variation induced by the discharge variation, which is related to the feedback effect. As a consequence, in this method, the backwater and the feedback effects are taken into account. For these two methods, the relative error is greater than $20 \%$ for one or both downstream boundary conditions considered.

\section{The response time along the channel reach}

It is often useful to know the response time not only at the downstream end of the channel, but also at any intermediate position. The test canal has been used to compute the response time at $90 \%$ using the different methods and for different intermediate positions. Figs. 7 and 8 show the results with the weir and the gate respectively.

Among the tested methods, the LBLR model is clearly the most accurate in terms of response time estimation all along the channel and for all values of $\alpha$. The calculation of $T_{A n k}$ is able to reproduce the evolution of $T_{S I C}^{(90)}$ all along the channel, but with less accuracy 


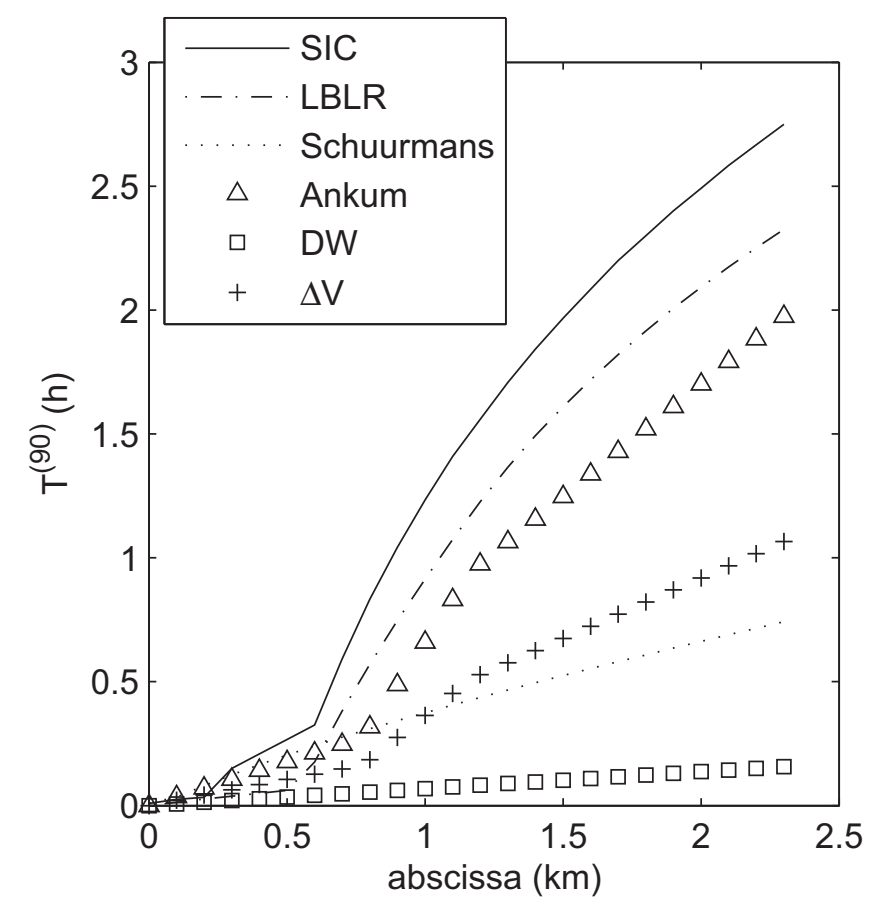

Fig. 8. Response time at $90 \%$ all along the channel with a gate at the downstream end.

than with the LBLR model. $T_{S c h}^{(90)}$ is clearly not suitable to estimate the response time at any intermediate position, especially with a gate at the downstream end.

\section{Validation on real data}

The LBLR method is now validated on a real canal. The reach considered here is $4.9 \mathrm{~km}$ long. It is part of the Gignac canal, located north west of Montpellier. The design profile of the canal is prismatic, which was verified in 2000 by a field survey with 191 cross sections. The bottom slope is $0.000244 \mathrm{~m} / \mathrm{m}$, the bottom width is $0.73 \mathrm{~m}$ and the bank slope is 0.93 $\mathrm{m} / \mathrm{m}$. The Manning coefficient is 0.025 , which corresponds to a rough concrete surface.

A gate at the upstream end of the reach allows the control of upstream discharge. A weir is located at the downstream end. It is $10 \mathrm{~m}$ long and $1.1 \mathrm{~m}$ high.

The simulated event is a flow release of $100 \mathrm{~L} / \mathrm{s}$ in October 2008 for an experiment described in Rabbani et al. (2009). The monitoring time step is $5 \mathrm{~min}$. The graph on the left in Fig. 9 shows the response at the downstream end to a step input. The solid line represents a fitted curve used to estimate the real response time. 
Author-produced version of the article published in Journal of Irrigation and Drainage Engineering, 2010, Volume 136, Issue 10, pp. 677-684. The original publication is available at http://ascelibrary.aip.org/iro/ doi: 10.1061/(ASCE)IR.1943-4774.0000241
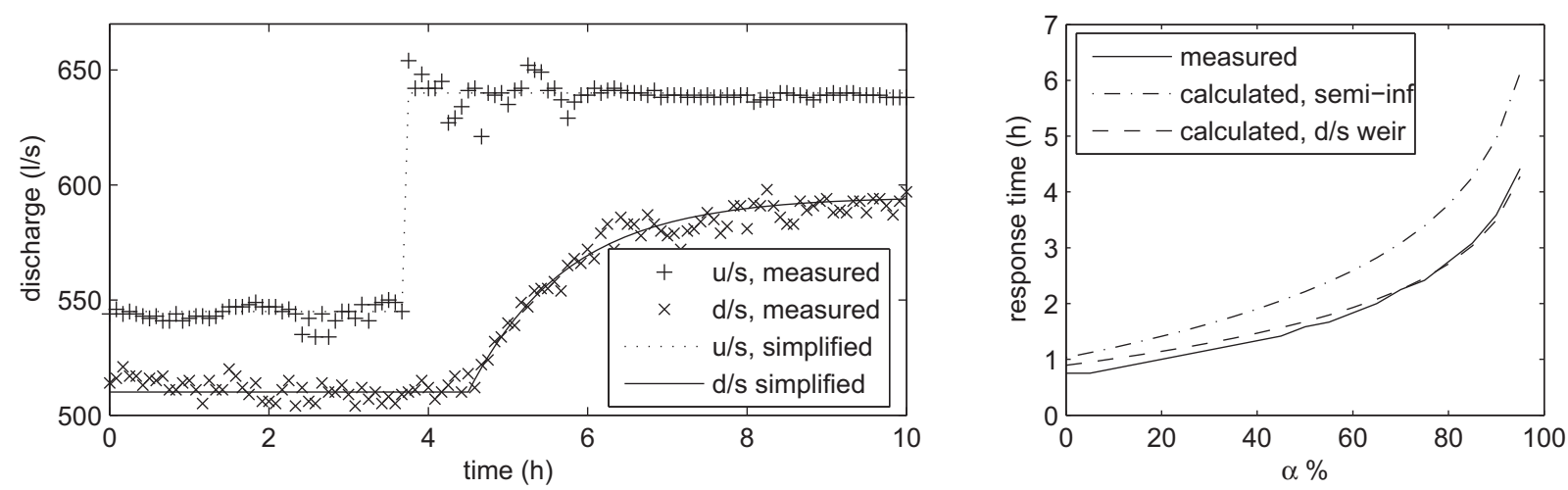

Fig. 9. Field measurements and response time approximation

The graph on the right shows the response time $T^{(\alpha)}$ with respect to $\alpha$. Measurements are compared with two approximations based on the LBLR method. For both approximations, characteristics of the equivalent canal are used. The first approximation assumes no downstream boundary condition (classical case of a semi-infinite channel) and the second one uses the characteristics of the weir to evaluate the downstream boundary condition.

Results clearly show that the LBLR method provides an accurate estimation of the response time of an open-channel. Besides, the weir at the downstream end significantly modifies the dynamics by introducing backwater and feedback effects. The LBLR model is able to take these effects into account.

\section{Design Application}

\section{Effects of the downstream boundary condition on the response time}

A design application is now presented. Considering the example canal described in Table 1, we analyze how the response time is affected by the weir length, the sill elevation or the gate opening. In this case, both $Y_{X}$ and $k$ may vary.

Fig. 10 and 11 show the relative response time at $90 \% T_{L B L R}^{(90) *}$ with respect to the relative downstream water depth $\left(Y_{X}^{*}=Y_{X} / Y_{n}\right)$ and the relative feedback $\left(k^{*}=k / k_{n}\right) . k_{n}$ can be calculated using the Manning equation that describes a uniform flow. For each downstream boundary condition $\left(Y_{X}, k\right), T_{L B L R}^{(90)}$ is normalized by the response time at $90 \%$ corresponding to $\left(Y_{n}, k_{n}\right)$. Consequently, the uniform flow corresponds to $Y_{X}^{*}=1$ and $k^{*}=1$; at this point, 


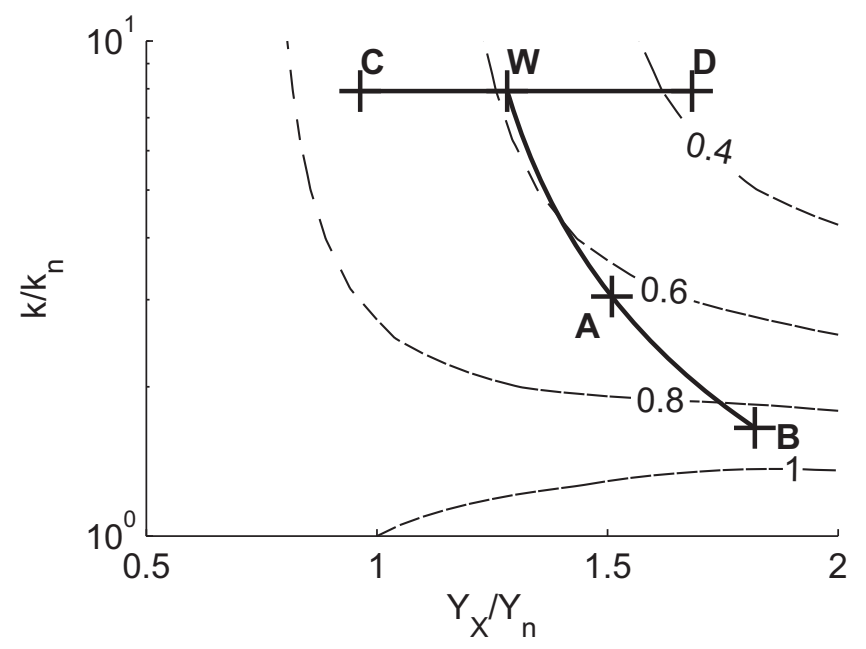

Fig. 10. Relative response time at $90 \%$ with respect to the relative downstream water depth $Y_{X}^{*}$ and the relative feedback $k^{*}$ with a weir at the downstream end.

the relative response time $T_{L B L R}^{(90) *}$ is equal to unity. Several points (W, G, A, B, C, D, E and F) have been added on these graphs to represent different downstream cross structures, defined in Table 2. Points $\mathrm{W}$ and $\mathrm{G}$ represent the weir and the gate previously defined, respectively.

Table 2. Characteristics of the different devices considered.

\begin{tabular}{ccc}
\hline Point & Device & Characteristics \\
\hline $\mathrm{W}$ & weir & height $=1.11 \mathrm{~m}$, length $=21 \mathrm{~m}$ \\
\hline $\mathrm{A}$ & weir & height $=1.11 \mathrm{~m}$, length $=5 \mathrm{~m}$ \\
$\mathrm{~B}$ & weir & height $=1.11 \mathrm{~m}$, length $=2 \mathrm{~m}$ \\
\hline $\mathrm{C}$ & weir & height $=0.8 \mathrm{~m}$, length $=21 \mathrm{~m}$ \\
$\mathrm{D}$ & weir & height $=1.5 \mathrm{~m}$, length $=21 \mathrm{~m}$ \\
\hline $\mathrm{G}$ & gate & opening $=0.32 \mathrm{~m}$ \\
\hline $\mathrm{E}$ & gate & opening $=0.4 \mathrm{~m}$ \\
$\mathrm{~F}$ & gate & opening $=0.28 \mathrm{~m}$ \\
\hline
\end{tabular}

This application provides a tool which may help the designer to fix the characteristics of the downstream structure according to response time objectives. For instance, let us consider a weir at the downstream end (Fig. 10). Changing its length (points W, A and B) has an effect on the backwater and on the feedback. However, the effect on the response time is rather limited $\left(T_{L B L R}^{(90) *}\right.$ varies from about 0.6 to 0.9$)$. On the contrary, if the sill elevation is 


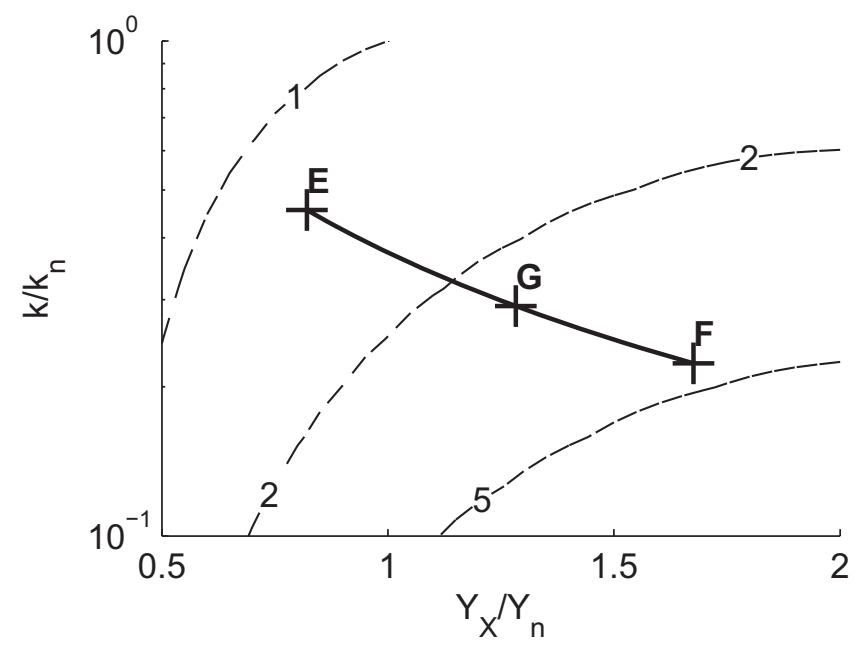

Fig. 11. Relative response time at $90 \%$ with respect to the relative downstream water depth $Y_{X}^{*}$ and the relative feedback $k^{*}$ with a gate at the downstream end.

doubled (point $\mathrm{C}$ to $\mathrm{D}$ ), the response time is divided by 2. Concerning the gate (Fig. 11), increasing the opening (point F to E) leads to a significant decrease of the response time.

One may also remark that each modification of the cross structure characteristics has a different impact on the flow dynamics. For instance, an increase of the downstream water depth (and then of the volume of the reach) can be obtained by increasing the sill elevation (C to $\mathrm{D}$ ), by decreasing the weir length (W to $\mathrm{B}$ ) or by decreasing the gate opening (E to $\mathrm{F})$. Yet, in the first case (C to D), the response time decreases, whereas it increases in the two other cases (W to B and E to F). Consequently, considering only the evolution of the downstream water depth is not sufficient to predict the evolution of the response time. It is essential to take the feedback effect into account, as well as the backwater effect.

\section{Influence of the reference discharge}

The last presented application concerns operation on irrigation canals. For management purposes, it is common to maintain the downstream water level at a specified value, which may be done by manipulating a gate at the downstream end of the reach.

In this application, the previous canal is considered with a gate at the downstream end. The downstream water depth is set to $1 \mathrm{~m}$, which is the normal depth corresponding to a discharge of $1.9 \mathrm{~m}^{3} / \mathrm{s}$. Then, we decrease the reference discharge from $1.9 \mathrm{~m}^{3} / \mathrm{s}$ to $0.5 \mathrm{~m}^{3} / \mathrm{s}$. 


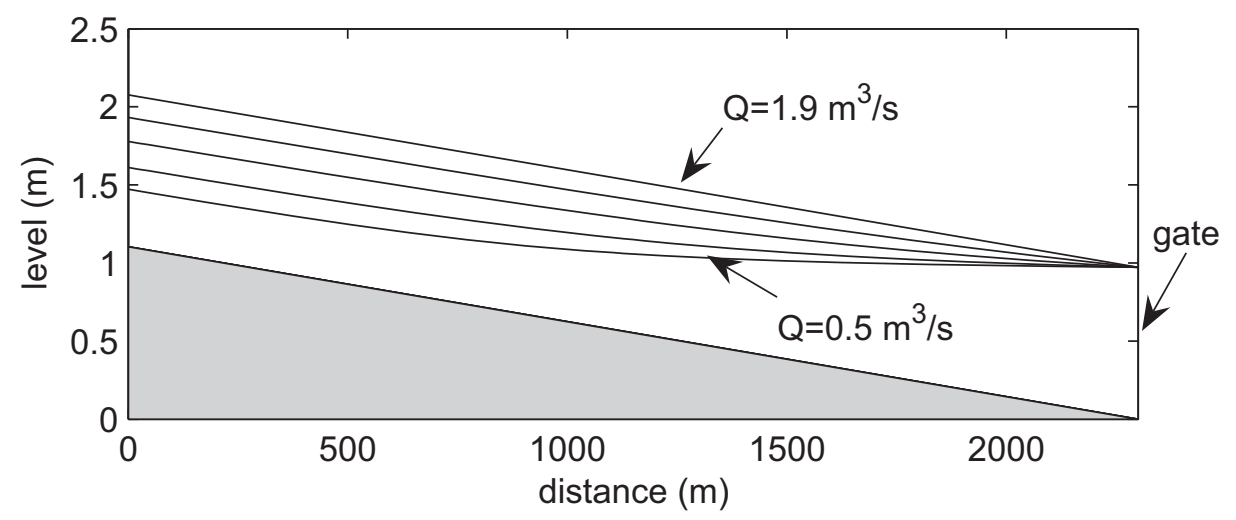

Fig. 12. Backwater curve for the different discharges.

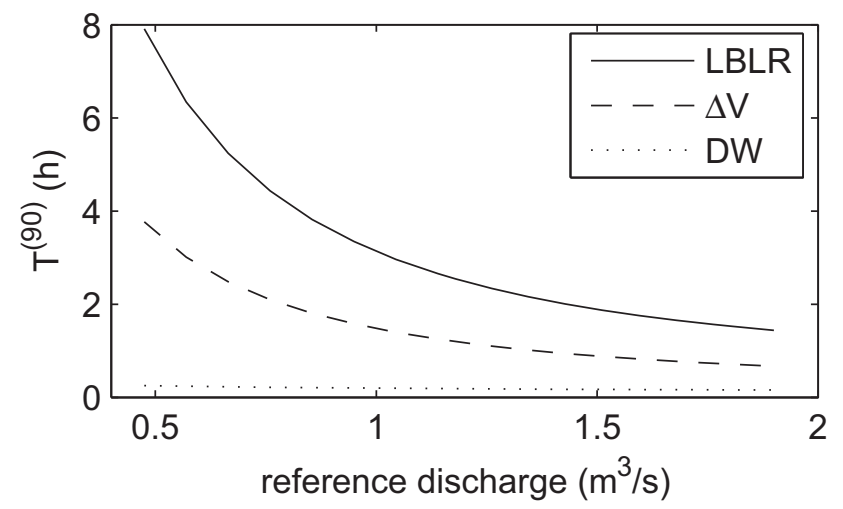

Fig. 13. Response time at $90 \%$ with respect to the reference discharge with a fixed downstream water level.

The gate opening is calculated for each discharge in order to maintain $Y_{X}$ equal to $1 \mathrm{~m}$. Fig. 12 represents the backwater curves for the different reference discharges. The method presented previously is then used to compute the response time at $90 \%$ for each discharge (see Fig. 13). $T_{D W}$ and $T_{\Delta \mathcal{V}}$ are also represented for comparison.

Results show that the response time may vary a lot according to the reference discharge. This kind of graph may be directly used for manual operations on an irrigation canal, in order to manage upstream releases according to the flow conditions and to the characteristics of the hydraulic cross structure.

\section{Conclusions}

This paper proposed a clarified description of the response-time of an irrigation canal. 
In particular, the difference between the response time, the travel time and the rising time has been pointed out. We presented a new method to estimate the response time. It is based on a physical approximation of the flow dynamics and allows to compute quickly the response time anywhere in the channel. The method takes the effects of a downstream cross structure into account, including the feedback effects as well as the backwater effects. It has been shown in this paper that both effects may have a large impact on the response time.

This new method can be used for feed-forward control problems, or for canal network management. For instance, it may help the canal designer to choose suitable characteristics of the downstream hydraulic structure according to the management objectives, when expressed as constraints on the response time. Finally, the method allows the manager of an irrigation canal to quickly estimate the response time according the reference discharge when a local controller is used to maintain the downstream water depth at a specified value.

\section{Acknowledgments}

This work was jointly supported by Region Languedoc Roussillon and Cemagref within the PhD thesis of Simon Munier, under the supervision of X. Litrico and G. Belaud. 


\section{Notation}

The following symbols are used in this paper:

$$
\begin{aligned}
& A=\text { wetted area }\left(\mathrm{m}^{2}\right) \\
& B=\text { channel width }(\mathrm{m}) \\
& C=\text { wave celerity }\left(\mathrm{ms}^{-1}\right) \\
& \mathrm{F}=\text { Froude number } \\
& g=\text { gravitational acceleration }\left(\mathrm{ms}^{-2}\right) \\
& k=\text { feedback coefficient }\left(\mathrm{m}^{2} \mathrm{~s}^{-1}\right) \\
& k^{*}=\text { normalized feedback coefficient }\left(\mathrm{m}^{2} \mathrm{~s}^{-1}\right) \\
& k_{n}=\text { feedback coefficient for the normal flow }\left(\mathrm{m}^{2} \mathrm{~s}^{-1}\right) \\
& m=\text { bank slope } \\
& n=\text { Manning coefficient }\left(\mathrm{sm}^{-1 / 3}\right) \\
& Q_{0}=\text { reference discharge }\left(\mathrm{m}^{3} \mathrm{~s}^{-1}\right) \\
& q=\text { discharge variations }\left(\mathrm{m}^{3} \mathrm{~s}^{-1}\right) \\
& S_{b}=\text { bottom slope } \\
& S_{f}=\text { friction slope } \\
& t=\text { time }(\mathrm{s}) \\
& T=\text { top width }(\mathrm{m}) \\
& T^{(\alpha)}=\text { response time at } \alpha \%(\mathrm{~s}) \\
& V=\text { flow velocity }\left(\mathrm{ms}^{-1}\right) \\
& x=\text { longitudinal abscissa }(\mathrm{m}) \\
& X=\text { channel length }(\mathrm{m}) \\
& Y=\text { water depth }(\mathrm{m}) \\
& y=\text { water depth variations }(\mathrm{m}) \\
& Y_{n}=\text { normal depth }(\mathrm{m}) \\
& Y_{X}=\text { downstream water depth }(\mathrm{m}) \\
& Y_{X}^{*}=\text { normalized downstream water depth }(\mathrm{m}) \\
& \tau, K=\text { parameters of the LBLR model (s) } \\
& \Delta \mathcal{V}=\text { dynamic storage }\left(\mathrm{m}^{3}\right)
\end{aligned}
$$


Author-produced version of the article published in Journal of Irrigation and Drainage Engineering, 2010, Volume 136, Issue 10, pp. 677-684. The original publication is available at http://ascelibrary.aip.org/iro/ doi: 10.1061/(ASCE)IR.1943-4774.0000241

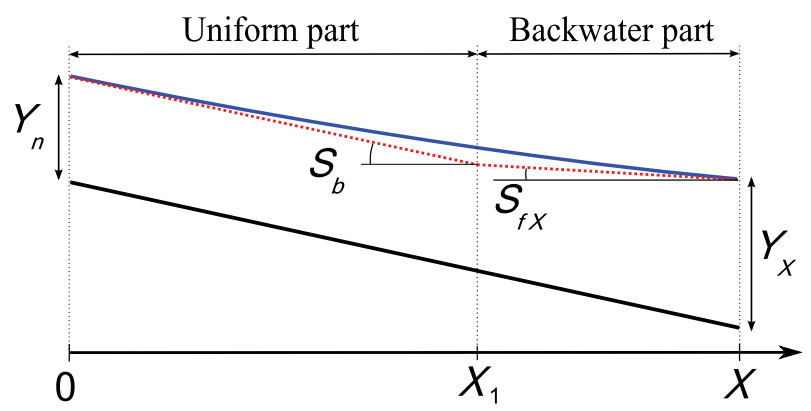

Fig. 14. Canal pool decomposition: uniform and backwater parts for the backwater curve approximation.

\section{Appendix I. Transfer function in the frequency domain}

Munier et al. (2008) linearized the Saint-Venant equations and used a backwater approximation to obtain the transfer function $T F(x, s)$ in the Laplace domain:

$$
q(x, s)=T F(x, s) q(0, s)
$$

where the Laplace variable is denoted $s$.

The backwater approximation consists in decomposing the channel into two sub-pools: a uniform part upstream and a backwater part downstream, designated by subscripts 1 and 2 respectively. The backwater curve is approximated by a straight line in each sub-pool. The abscissa of the separation between the two parts is denoted $X_{1}$ and defined as shown on Fig. 14. The slope $S_{X}$ of the backwater curve at the downstream end is given by:

$$
S_{X}=\left.\frac{d Y}{d x}\right|_{X}=\frac{S_{b}-S_{f X}}{1-\mathrm{F}_{X}^{2}}
$$

where $S_{f X}$ is the friction slope and $\mathrm{F}_{X}$ the Froude number, calculated at the downstream end of the reach $(x=X)$.

The downstream boundary condition is given by the couple $\left(Y_{X}, k\right)$, where $Y_{X}$ is the downstream water depth and $k$ the feedback coefficient. The decomposition is determined using the characteristics of the channel and $Y_{X}$, and leads to the length $X_{i}$ and the mean water depth $Y_{i}$ for each sub-pool $(i=1,2)$. Knowing $Y_{i}$, each of the following variables can 
Author-produced version of the article published in Journal of Irrigation and Drainage Engineering, 2010, Volume 136, Issue 10, pp. 677-684. The original publication is available at http://ascelibrary.aip.org/iro/

doi: 10.1061/(ASCE)IR.1943-4774.0000241

be computed for each sub-pool: $T_{i}, P_{i}, A_{i}, V_{i}, C_{i}$ and $\kappa_{i}, i=1,2$, where $T$ is the top width (m), $P$ the wetted perimeter $(\mathrm{m}), A$ the wetted area $\left(\mathrm{m}^{2}\right), V=Q_{0} / A$ the mean velocity $\left(\mathrm{ms}^{-1}\right), C=\sqrt{g A / T}$ the wave celerity and $\kappa$ is a parameter defined as below:

$$
\kappa=\frac{7}{3}-\frac{4}{3} \frac{A}{T P} \frac{\partial P}{\partial Y}
$$

We define, for $i=1,2$ :

$$
\begin{aligned}
& \lambda_{i 1}=a_{i}+b_{i} s-\sqrt{a_{i}^{2}+2 a_{i} c_{i} s+\left(2 a_{i} d_{i}+c_{i}^{2}\right) s^{2}} \\
& \lambda_{i 2}=a_{i}+b_{i} s+\sqrt{a_{i}^{2}+2 a_{i} c_{i} s+\left(2 a_{i} d_{i}+c_{i}^{2}\right) s^{2}}
\end{aligned}
$$

with $\quad a_{i}=\frac{g S_{b}\left(1+\kappa_{i}\right)}{2\left(C_{i}^{2}-V_{i}^{2}\right)}, \quad b_{i}=\frac{V_{i}}{C_{i}^{2}-V_{i}^{2}}, \quad c_{i}=\frac{V_{i}}{C_{i}^{2}-V_{i}^{2}}+\frac{2}{V_{i}\left(1+\kappa_{i}\right)}, \quad d_{i}=\frac{1}{2 a_{i}}\left(\frac{C_{i}^{2}}{\left(C_{i}^{2}-V_{i}^{2}\right)^{2}}-c_{i}^{2}\right)$.

We also define:

$$
\rho_{i}=\frac{k_{i} \lambda_{i 1}+T_{i} s}{k_{i} \lambda_{i 2}+T_{i} s}
$$

with $k_{1}=-T_{2} s \frac{1-\rho_{2} e^{\left(\lambda_{21}-\lambda_{22}\right) X_{2}}}{\lambda_{21}-\lambda_{22} \rho_{2} e^{\left(\lambda_{21}-\lambda_{22}\right) X_{2}}}$ and $k_{2}=k$.

Under these assumptions and given the upstream discharge, the discharge at any position can be obtained using the Saint-Venant transfer function:

$$
T F(x, s)= \begin{cases}\frac{1-\rho_{1} e^{\left(\lambda_{11}-\lambda_{12}\right)\left(X_{1}-x\right)}}{1-\rho_{1} e^{\left(\lambda_{11}-\lambda_{12}\right) X_{1}}} e^{\lambda_{11} x} & \text { if } x \leq X_{1} \\ \frac{\left(1-\rho_{1}\right) e^{\lambda_{11} X_{1}}}{1-\rho_{1} e^{\left(\lambda_{11}-\lambda_{12}\right) X_{1}}} \frac{1-\rho_{2} e^{\left(\lambda_{21}-\lambda_{22}\right)\left(X_{2}-\left(x-X_{1}\right)\right)}}{1-\rho_{2} e^{\left(\lambda_{21} \lambda_{22}\right) X_{2}}} e^{\lambda_{21}\left(x-X_{1}\right)} & \text { if } x>X_{1}\end{cases}
$$

The expression of the Saint-Venant transfer function is generally too complex to be easily inverted back to the time domain explicitly, so an approximation is required to get the response in the time domain. To that purpose, the classical moment matching method (Dooge et al. 1987; Munier et al. 2008) is used to derive an approximate first-order-with- 
delay model for flow routing (Eq. (16)).

$$
\widetilde{T F}(x, s)=\frac{G(x) e^{-\tau(x) s}}{1+K(x) s}
$$

The purpose of the moment matching method is to match the moments of the exact transfer function $T F(x, s)$ to those of the approximate one $\widetilde{T F}(x, s)$, which ensures a good representation for the low frequency range. To obtain the first three moments of the exact transfer function, the Taylor series expansion of $T F(x, s)$ is first computed, leading to:

$$
T F(x, s)=A(x)+B(x) s+C(x) s^{2}+o\left(s^{2}\right)
$$

Details of the computation are given in appendix II.

One may note that, according to the continuity equation, the coefficient $A(x)$ is equal to unity, which leads to $G(x)=1$.

Then the moment matching method leads to the following system:

$$
\begin{aligned}
K(x) & =\sqrt{2 C(x)-B(x)^{2}} \\
\tau(x) & =-B(x)-\sqrt{2 C(x)-B(x)^{2}}
\end{aligned}
$$

This method provides a low frequency approximation of the flow transfer and leads to an analytical and distributed expression of the model parameters. The time delay $\tau(x)$ and the time constant $K(x)$ are obtained as analytical functions of the feedback coefficient $k$ and the physical parameters of the pool (geometry, friction, discharge, downstream water depth).

According to Eq. (16), the output $q(x, t)$ for a step input is:

$$
q(x, t)=\left(1-e^{-\frac{t-\tau(x)}{K(x)}}\right)
$$

This expression allows us to easily compute the response time. 
Author-produced version of the article published in Journal of Irrigation and Drainage Engineering, 2010, Volume 136, Issue 10, pp. 677-684. The original publication is available at http://ascelibrary.aip.org/iro/ doi: 10.1061/(ASCE)IR.1943-4774.0000241

\section{Appendix II. Taylor Series of the Saint-Venant Transfer Function}

The moment matching method is used to approximate the transfer function by a firstorder-plus-delay. To apply this method, we compute the Taylor series of the transfer function.

$$
\rho_{i}=B_{\rho i} s+C_{\rho i} s^{2}+o\left(s^{2}\right)
$$

$$
\begin{aligned}
& B_{\rho i}=\frac{\left(b_{i}-c_{i}\right) A_{k i}+T_{i}}{2 a_{i} A_{k i}} \\
& C_{\rho i}=\frac{-1}{2 a_{i} A_{k i}}\left[d_{i} A_{k i}+\frac{1}{2 a_{i} A_{k i}}\left(\left(b_{i}+c_{i}\right) A_{k i}+T_{i}\right)\left(\left(b_{i}-c_{i}\right) A_{k i}+T_{i}\right)+T_{i} \frac{B_{k i}}{A_{k i}}\right]
\end{aligned}
$$

with

$$
k_{1}=A_{k 1}+B_{k 1} s+o(s)
$$

$$
\begin{array}{cc}
A_{k 1}=\frac{k}{1-\left(1+k \frac{b_{2}-c_{2}}{T_{2}}\right)\left(1-e^{-2 a_{2} X_{2}}\right)} & \\
B_{k 1}=\frac{-A_{k 1}^{2}}{T_{2}}\left[d_{2}+\left(2 c_{2} B_{\rho 2}+2 a_{2}\left(C_{\rho 2}-2 c_{2} X_{2} B_{\rho 2}+B_{\rho 2}^{2} e^{-2 a_{2} X_{2}}\right)\right) e^{-2 a_{2} X_{2}}\right] \\
k_{2}=A_{k 2}+B_{k 2} s
\end{array}
$$

$A_{k 2}=k$

$B_{k 2}=0$

For each sub-pool $(i=1 . .2)$, we define $Z_{i}(x)$ and $T F_{i 0}(x)$ as following:

$$
Z_{i}(x)=\frac{1-\rho_{i} e^{\left(\lambda_{i 1}-\lambda_{i 2}\right)\left(X_{i}-x\right)}}{1-\rho_{i} e^{\left(\lambda_{i 1}-\lambda_{i 2}\right) X_{i}}}=1+B_{Z i}(x) s+C_{Z i}(x) s^{2}+o\left(s^{2}\right)
$$

$$
\begin{aligned}
B_{Z i}(x)= & -B_{\rho i}\left(1-e^{-2 a_{i} x}\right) e^{-2 a_{i}\left(X_{i}-x\right)} \\
C_{Z i}(x)= & -\left[\left(C_{\rho i}-2 B_{\rho i} c_{i} X_{i}+B_{\rho_{i}}^{2} e^{-2 a_{i} X_{i}}\right)\left(1-e^{-2 a_{i} x}\right)+2 B_{\rho i} c_{i} x\right] e^{-2 a_{i}\left(X_{i}-x\right)} \\
& T F_{i 0}(x)=Z_{i}(x) e^{\lambda_{i 1} x}=1+B_{i 0}(x) s+C_{i 0}(x) s^{2}+o\left(s^{2}\right) \\
B_{i 0}(x)= & \left(b_{i}-c_{i}\right) x+B_{Z i}(x) \\
C_{i 0}(x)= & \left(b_{i}-c_{i}\right)^{2} \frac{x^{2}}{2}-d_{i} x+\left(b_{i}-c_{i}\right) x B_{Z i}(x)+C_{Z i}(x)
\end{aligned}
$$


Author-produced version of the article published in Journal of Irrigation and Drainage Engineering, 2010, Volume 136, Issue 10, pp. 677-684. The original publication is available at http://ascelibrary.aip.org/iro/ doi: 10.1061/(ASCE)IR.1943-4774.0000241

if $x<X_{1}$

$$
T F(x, s)=T F_{10}(x)=1+B(x) s+C(x) s^{2}+o\left(s^{2}\right)
$$

$$
\begin{gathered}
B(x)=B_{10}(x) \\
C(x)=C_{10}(x) \\
\quad \text { if } x>X_{1}
\end{gathered}
$$

$$
T F(x, s)=T F_{10}\left(X_{1}\right) T F_{20}\left(x-X_{1}\right)=1+B(x) s+C(x) s^{2}+o\left(s^{2}\right)
$$

$$
\begin{aligned}
& B(x)=B_{10}\left(X_{1}\right)+B_{20}\left(x-X_{1}\right) \\
& C(x)=C_{10}\left(X_{1}\right)+B_{10}\left(X_{1}\right) B_{20}\left(x-X_{1}\right)+C_{20}\left(x-X_{1}\right)
\end{aligned}
$$

The two parameters $\tau(x)$ and $K(x)$ of the first-order-with-delay are obtained by:

$$
\begin{aligned}
K(x) & =\sqrt{2 C(x)-B(x)^{2}} \\
\tau(x) & =-B(x)-\sqrt{2 C(x)-B(x)^{2}}
\end{aligned}
$$

\section{References}

Ankum, P. (1995). Flow Control in Irrigation and Drainage. IHE Delft. The Netherlands.

Baume, J.-P., Malaterre, P.-O., Belaud, G., and Le Guennec, B. (2005). "SIC: a 1D hydrodynamic model for river and irrigation canal modeling and regulation." Métodos Numéricos em Recursos Hidricos, 7, 1-81.

Bautista, E. and Clemmens, A. J. (1999). "Computerized anticipatory control of irrigation delivery systems." Workshop on Modernization of Irrigation Water Delivery Systems, U.S. Committee on Irrigation and Drainage (USCID), Phoenix, Arizona. 359-373.

Burt, C. M. and Plusquellec, H. L. (1990). "Water delivery control." Management of Farm Irrigation Systems. American Society of Agricultural Engineers, St. Joseph, MI., 373-423. 
Dooge, J., Napiórkowski, J., and Strupczewski, W. (1987). "Properties of the generalized downstream channel response." Acta Geophysica Polonica, 35(4), 405-418.

Litrico, X. and Fromion, V. (2004a). "Frequency modeling of open-channel flow." Journal of Hydraulic Engineering, 130(8), 806-815.

Litrico, X. and Fromion, V. (2004b). "Simplified modeling of irrigation canals for controller design." Journal of Irrigation and Drainage Engineering, 130(5), 373-383.

Munier, S., Litrico, X., Belaud, G., and Malaterre, P.-O. (2008). "Distributed approximation of open-channel flow routing accounting for backwater effects." Advances in Water Resources, 31(12), 1590-1602.

Munier, S. (2009). "Modélisation intégrée des écoulements pour la gestion en temps réel d'un bassin versant anthropisé." PhD thesis, AgroParisTech.

Rabbani, T., Munier, S., Dorchies, D., Malaterre, P.-O., Bayen, A., and Litrico, X. (2009). "Flatness-based control of open-channel flow in an irrigation canal using SCADA." IEEE Control Systems Magazine, 29, 22-30.

Schuurmans, J., Bosgra, O., and Brouwer, R. (1995). "Open-channel flow model approximation for controller design." Applied Mathematical Modelling, 19(9), 525-530.

Schuurmans, W. (1990). "Analytical formulae for the response time of irrigation canals." Irrigation and Drainage Systems, 4(1), 37-58.

Strelkoff, T. S., Deltour, J. L., Burt, C. M., Clemmens, A. J., and Baume, J. P. (1998). "Influence of canal geometry and dynamics on controllability." Journal of Irrigation and Drainage Engineering, 124(1), 16-22. 